\title{
Social Functions of Conditional Apologies in Business Communication
}

\author{
Xing Zhang* \\ College of Foreign Studies, Jinan University, China \\ Corresponding Author: Dr. Xing Zhang, E-mail: maggiezhang@jnu.edu.cn
}

\author{
ARTICLE INFO \\ Article history \\ Received: March 04, 2018 \\ Accepted: May 05, 2018 \\ Published: September 01, 2018 \\ Volume: 7 Issue: 5 \\ Advance access: July 2018
}

Conflicts of interest: None

Funding: This paper is

supported by the

Fundamental Research

Funds for the Central

Universities (grant no.

15JNYH007) -

Constructing a Semantic

Knowledge Network of

English Words: A

Multimodal Perspective.

\begin{abstract}
The objective of this study is to investigate what social functions conditional apologies perform. To this end, naturally occurring conditional apologies were identified in an authentic business corpus, the Cambridge Business English Corpus (CBEC). From the perspective of speakers' face needs, two research questions were discussed. The first question asks what the functions are that conditional apologies are employed to fulfil when used by speakers. The second question is whether conditional apologies are oriented towards the speaker's positive needs. In the spoken and written corpora of the CBEC, occurrences of sorry-based expressions (sorry and I'm sorry) collocating with if are extracted, and the ratios of occurrences of conditional apologies to all apologies of sorry-based expression are compared. Our findings indicate that in business communication, the conditional apology could be used as a downgrading strategy for the purpose of denying full responsibility and decreasing face-threat to the speakers. The conditional apology could also be used by speakers to distance themselves from the offense, question the offensiveness of the event and to deny the speaker's knowledge of it or involvement in it. Furthermore, through analysis of real examples, conditional apologies are determined to be driven by a desire to satisfy the speaker's positive face needs in these contexts. In addition, our observation reveals that there is a tendency for the conditional apology to be used with a coordinating conjunction but to add a contrast statement in order to add detailed explanation regarding the causes of those offenses.
\end{abstract}

Key words: Conditional Apology, Social Functions, Positive Needs

\section{INTRODUCTION}

\section{Face and Apology}

The notion of face is defined as the "positive social value a person effectively claims for himself by the line others assume he has taken during a particular contact" (Goffman, 1955: p.5). In social interactions, it is natural for participants to maintain and protect face in interactions, and acts that violate or fail to satisfy face needs are considered to be face-threatening acts (Brown \&Levinson, 1987). In addition, an apology is one of these important facework strategies used to repair damages caused by face-threatening acts in various types of interactions.

Multiple definitions of apology have been proposed from different perspectives, such as "social acts conveying affective meaning" (Holmes, 1990: p.155), or "compensatory action to an offence in the doing of which the $\mathrm{S}$ (speaker) was causally involved and which is costly to the H (hearer)" (Kasper \& Blum-Kulka, 1993: p.82). Holmes (1990) defines apology as a speech act addressed to B's face-needs and intended to remedy an offence for which A takes responsibility and thus to restore equilibrium between $\mathrm{A}$ and $\mathrm{B}$ (where $\mathrm{A}$ is the apologizer, and B is the person offended). Brown and
Levinson (1987) described negative face as the want that one's actions be unimpeded by others, while positive face is the desire for one's wants to be desirable to others (62). Ogiermann (2009) agreed that S's positive face is the desire to be liked by and share wants with others (p. 52).

\section{Conditional Apology}

Conditional apology was defined by Kitao S. and Kitao K. (2013) as an apology that makes use of a conditional form, e.g., "I'm sorry if you were offended". Research regarding conditional apologies is quite limited (Miller, 2014), even though apology has been studied intensively in numerous studies. There has also been disagreement regarding its function in the context of adopting apologies in the conditional form. Shuman (1999) alleged that the conditional apology was not an apology at all, as "couching an offer to apologize in conditional terms" called its sincerity into question (p. 186). In addition, Eisinger (2011) also claimed that the conditional apology is one of the more common types of non-apology (p. 137). Friedman (2006) noted that since a conditional apology does not usually indicate remorse, it cannot be counted as effective apology. Ogiermann (2009) mentioned that in 
her material, there was only one instance of sorry combined with a conditional clause introduced by if, and she believed its function "briefly takes up the offence while indirectly questioning its existence". However, Miller (2014) supported the claim that conditional apologies can be meaningful and genuine, as such apologies could be "non-deceptive and appropriately genuine" (p. 406). This researcher also acknowledged that conditional apologies have been largely understudied, thereby calling for a more "nuanced account of being genuine" (p. 406) to access the degree of genuineness of an apology, e.g., being absolutely genuine or being relatively genuine.

In line with the abovementioned issues, the current research intends to investigate what interactional functions conditional apology can perform when incorporated into the framework of face theory as proposed by Brown and Levinson (1987). This study seeks an answer to the following two questions: the first question is what interactional functions the conditional apology can accomplish in real business interactions. The second question is to determine whether a conditional apology is actually oriented towards the speaker's positive needs.

\section{LITERATURE REVIEW}

\section{Apologies in Business Settings}

There has been a growing body of literature on apologies in business settings (e.g., Bisel \& Messersmith, 2012; Hoffman, 1988, Levi, 1997; Trosborg \& Shaw, 1998; Čubajevaite \& Ruzaite, 2007). As early as twenty years ago, Hoffman (1998) examined apologies used in employment termination cases to discuss why an effective apology could resolve disputes and what constitutes an effective apology, as well as its legal consequences. Under the context of workplace relationships, Davila (2004) proposed a theoretical model to combine "three of the hypothesized antecedents of forgiveness: offense severity, the content of the apology and the perceived sincerity of the offender's sincerity" (p. 795). Čubajevaite and Ruzaitè (2007) investigated the routine of apologizing in the spoken business corpus of the British National Corpus. They claimed that apologies were of special importance as they could increase respect and stabilize relationships between colleagues in business communication. Additionally, they classified the faults of these apologies into linguistic malfunctioning and non-linguistic malfunctioning reasons.

\section{Social Functions of Apologies}

Focusing on remedial exchange, Goffman (1971) described the social functions of the apology as compensatory actions for restoring and maintaining social harmony. This researcher noted that those acts of remedial work allow "the participants to go on their way, if not with satisfaction that matters are closed, then at least with the right to act as if they feel that matters are closed and that ritual equilibrium has been restored" (p. 140).

When Norrick (1978) extended the discussion of illocutionary acts of apology originally classified as expressive in Searle (1976), he defined the social functions of speech acts as "effects which a speaker intends to cause by performing such acts" (p. 280). According to Norrick, the social functions of apologies include serving "to evince good manners, to assuage the addressee's wrath, or simply to get off the hook and be on one's way" (1978: 280). This researcher also listed possible reasons for why we apologize, such as "to appease people we have injured, to avoid accusations and/or reprisals, to implicate contrition, and, of course, to elicit acts of forgiving and be freed from guilt (Norrick, 1978: 280). On a similar note, Fraser (1981) described how the offender may try to make things right, "thereby relieving himself of some if not all of the associated moral responsibility" (p.259). Edmondson (1981) recognized the illocutionary force of apology as an attempt to restore social harmony, claiming its most predictable function as an attempt on the part of S to cause $\mathrm{H}$ to "withdraw a preceding complaint" (p. 280).

\section{Speaker's Face Orientation}

As noted by Ogiermann (2009), there has been considerable controversy regarding whether it is the speaker (S)'s or the hearer $(\mathrm{H})$ 's face that apologies redress. A number of studies considered the apologies to be acts oriented towards the H's face needs (Brown \& Levinson, 1978; Holmes 1989, 1995). For example, Brown and Levinson (1987:68) asserted that apologies threaten S's positive face because they directly damage S's positive face wants (that S's actions to be approved and liked). Edmondson and House (1981) stated that the act [of apology] was "highly hearer-supportive and often self-demeaning" (p. 45), as it could "placate the hearer" and "restore one's own social status" (p. 153). Holmes defended apologies as being "addressed to H's face needs and intended to remedy an offense for which S takes responsibility (1995: 155). Olshtain (1989) believed apologies were "face-saving for the $\mathrm{H}$ and face-threatening for the S" (p.156), as they were used by S to restore H's face which was damaged by the offense, which is costly to H's own face, whereas Meier (1992) argued that the apology was remedial work used as a face-saving device "as regards S (not H)" (p. 31), with an intention to repair S's image or save S's face. She then claimed that "concern for H's face is only a by-product" of such an intention (p. 31). Ogiermann (2009) supported this view that apologies could restore the speaker's positive face, namely, "the desire to be liked by and share wants with others" (p. 52), thereby motivating apology, instead of being damaged by it. Her reason is that S's positive face is central to all apologies because we would have no reason to humiliate ourselves by attempting to set things right if we did not care about our image in others' eyes.

This school of views seems to highlight the importance of the speaker's face needs in affecting ways in which conditional apologies are adopted. Therefore, this paper tends to explore these naturally occurring conditional apologies from the perspective of the speaker's positive needs by adopting Brown and Levinson's Face Theory.

\section{METHODOLOGY}

Previous empirical research on apologies has relied heavily on data elicited via discourse completion tasks, a meth- 
od originally developed by Blum-Kulka and Olshtain (1984), which has been adopted by other scholars, as well (e.g. Kasper, 1989; Nureddeen, 2008; Ogiermann, 2008, 2009; Jebahi, 2011). However, it is undeniable that naturalistic apologies cannot be produced when elicited by business communication (Filimonova, 2016), as a compromise exists between authenticity of language and the control of multiple situational factors (cf. Kasper, 2000; Félix-Brasdefer, 2010).

Considering this possibility, the present study is conducted on a naturalistic corpus, Cambridge Business English Corpus (CBEC) from Cambridge International Corpus. CBEC is a huge collection of British and American business materials in different aspects, such as reports, documents, books, and the business sections in newspapers. The Cambridge Business English Corpus also includes the Cambridge and Nottingham Spoken Business English Corpus (CANBEC), a joint project between Cambridge University Press and Nottingham University which contains recordings of formal and informal meetings, presentations, telephone conversations and lunchtime conversations from companies of all sizes.

\section{DATA ANALYSIS}

This study utilizes CANBEC as the spoken sub-corpus, and CBEC as the written sub-corpus. The statistics of these two sub-corpora are shown in Table 1.

In Table 1, the number of tokens in the written sub-corpus is more than 5 times more than those in spoken sub-corpus, and the number of words is also nearly 5 times more than those in spoken sub-corpus.

Table 2 shows the co-occurrence counts of sorry and if in spoken sub-corpus and written sub-corpus. The collocations of sorry found in CANBEC and CBEC provide some preliminary observations as to the distribution of conditional apologies in both sub-corpora. Co-occurrence count is the number of cases when sorry (or a sorry-based expression) collocates with if, which is considered to be a conditional apology in this study. The candidate count is the number of occurrence of if in this sub-corpus. Ratio refers to the occurrences of conditional apologies to all apologies in the form of sorry-based expressions.

In CANBEC, we extract 16 occurrences of sorry-based expression (sorry or I'm sorry) collocating with if, while the number of sorry-based expressions is 1,188 cases. In CBEC, there are 71 occurrences out of 3,472 cases of sorry-based

Table 1. Statistics of spoken and written sub-corpus

\begin{tabular}{lcc}
\hline Sub-corpora & Tokens & Words \\
\hline Spoken & $4,925,395$ & $4,122,428$ \\
Written & $254,968,571$ & $213,402,094$ \\
\hline
\end{tabular}

apologies. In comparison, the ratio of occurrences of conditional apology to all apologies of sorry-based expressions in the written sub-corpus is nearly twice that in the spoken sub-corpus. As shown in Table 2, The Mutual Information score expresses the extent to which sorry co-occurs with if compared to the number of times they appear separately. The T-score expresses the certainty with which we can evaluate how strong the association between sorry and if is, i.e. to conclude their co-occurrence is not random, at least. In Table 2, the T-score of sorry and if is more than twice that of the written sub-corpus. Considering that very frequent word combinations tend to reach a high T-score value even they are not significant as collocations, this result shows the association between sorry and if in the written sub-corpus is stronger than that in the spoken sub-corpus.

\section{Excerpt 1}

Speaker 1: I'm sorry if my statement misled the sergeant. Speaker 1: My nerves are on edge.

Speaker 2: You should consult a qualified psychiatrist.

The speaker expressed his apology, but he adopted a conditional clause to question the offensiveness of this event. This attempt to mitigate the severity of this offense is reflected in using "if my statement misled the sergeant", rather than "that my statement misled the sergeant". The speaker also added an explanation to his action. The hearer did not accept this apology, but responded with a remedial suggestion to imply that the speaker's action did have bad influence even though he was not willing to face the severity of its consequences. However, the speaker initiated this conditional apology because he was driven by his desire to be liked by the hearer or be considered as responsible by the hearer.

\section{Excerpt 2}

Speaker 1: Oh, sorry if I was being a bit off this morning, but I had about enough.

Speaker 2: Well I gathered. I gathered.

Speaker 1: Paul phoned.

Speaker 2: Hey?

In this case, the speaker apologized with a conditional clause to maintain his image for the sake of meeting a social norm, i.e. to be liked by others when he was not sure whether his earlier action damaged his image. Moreover, his apology was followed by an explanation to justify his behaviour in order to get the hearer's understanding. As such, this conditional apology was driven by the hope of satisfying the speaker's positive face needs and for the purpose of denying his awareness of this offense or even question the offensiveness of it. The implication by this conditional apology is that the speaker himself may not be off at all.

Table 2. Ratio of conditional apology to all apologies in spoken and written sub-corpus

\begin{tabular}{lcccccc}
\hline Sub-corpus & $\begin{array}{c}\text { Co-occurrence } \\
\text { count of sorry } \text { and } \text { if }\end{array}$ & $\begin{array}{c}\text { Count of sorry-based } \\
\text { expressions }\end{array}$ & Ratio & Candidate count & T-score & MI \\
\hline Spoken & 16 & 1,188 & 0.01 & 12,910 & 3.997 & 10.959 \\
Written & 76 & 3,472 & 0.02 & 276,206 & 8.366 & 7.143 \\
\hline
\end{tabular}




\section{Excerpt 3}

Speaker 1: I did update these. I don't know if you've been updating them. Erm Circuit erm obviously this is Thursday. No update.

Speaker 1: Sorry if you can't see this. Couple of Sara-Jane's. Er on that's today isn't it.

Speaker 2: Right. Right. Right.

Speaker 1: Erm guess I'll do that. You've written a fairly good P R S again.

In this conversation, the speaker apologized if the hearer did not get the updates. His unwillingness to accept full responsibility is reflected in this conditional apology, which sounds more similar to a means to distance himself from the offense that the hearer failed to get an update. The hearer did not respond to his apology at the next turn, so the speaker kept on explaining until the hearer uttered Right as a sign of uptake. This conditional apology is an attempt to excuse the speaker's involvement in the offence, which is motivated to satisfy his own face's needs, since he provided many explanation before his apology.

\section{Excerpt 4}

Speaker 1: So sorry if I'm harping on and whatever, but it's my job to harp on when the figures are down.

Speaker 2: Stage where we start looking at the likes of Post Office and erm A V A. However, A V A are getting unhappy with me at the moment because we were to see them on the twenty-fifth of September, and we still don't have anything to show them.

Speaker 2: And there's a lot of product there for us.

In this conversation, the speaker used a conditional clause to apologize, saying "if" he was harping on, rather than "sorry" that he's harping on, in order to downgrade the severity of the offense. This attempt enabled the speaker to create a distance from the offense, serving the purpose of denying full responsibility. Thus, this apology decreases the face-threat to the speaker, for his willingness to apologize indicates that he cares for his image or face even though he does not take full responsibility. His apology did not get excused or rejected as generally apologetic terms from other participants in the meeting, but it was responded to with an explanation about what their difficulties were and why they were in the current situation, which implies that the other hearers were aware that the drive for the speaker's apology is mainly to maintain his own face.

\section{Excerpt 5}

Speaker 1: However, he just never does anything about it. However, anyway. Right.

Speaker 2: Can I just raise something on Sorry if I may Ralph.

Speaker 2: Go on.

In this interaction, this speaker added an apology after he asked for permission to change the subject to another issue. His apology, a combination of sorry and a conditional clause, was used to show his awareness of the offensiveness of this interruption. Even though he has already asked for permission with a polite question, this conditional apology was orientated towards his need to sound considerate towards other participants in the conversation. His concern received positive feedback when the hearer replied "go on" to indicate that the hearer did not mind the topic being shifted, which also implicitly showed that this apology was received as more of a request.

\section{Excerpt 6}

I'm sorry if this appears to be looking a gift horse in the mouth but these things do occur.

This apologizer made a formal apology by the use of a rather formal expression-'I'm sorry" instead of the short form "sorry", then an if-introduced clause to show concession in this apology and to imply that this possibly would not be looking a gift horse in the mouth. This can be considered as an act to question whether this event is actually offensive as far as the apologizer is concerned. Nevertheless, the apologizer still expressed his apology, an act that is driven by his positive face needs to be liked by the hearer.

\section{FINDINGS AND CONCLUSIONS}

As noted above, the originality of this research lies in its empirical analysis of natural examples of conditional apologies in the form of combinations of sorry and sorry-based expressions with if from the perspectives of speakers' face needs. This study discusses how conditional apologies perform various social functions in authentic business corpora adopting the concept of face from Brown and Levinson's (1987) politeness theory. After extracting and examining all of the collocates of sorry (sorry-based expression) and if in Cambridge Business English Corpus, we find that conditional apologies are generally used to accept partial responsibility for offenses caused by the speaker so the face-threat to the speaker would be downgraded in interactions. For instance, in certain contexts, they could be used by speakers to mitigate the severity of an offense or to avoid being involved with the offense by distancing themselves from the offense. More often than not, the doubts regarding whether the event is offensive or not or whether the speakers have knowledge of this offence could also be reflected in conditional apologies. Most importantly, it is found that these conditional apologies could be oriented towards satisfying speakers' positive face needs, as they are motivated by the speaker's desires to be liked by other participants in the conversation, despite their unwillingness to accept full responsibility for these offenses.

In addition, our observation also reveals that there is a tendency for conditional apologies to be used with a coordinating conjunction, but, to add a contrast statement. Among the 16 cases of conditional apology, 4 are used with but to give information contrasting the previous statement, while there are 13 cases in written corpora when conditional apologies are used with those but-introduced conjunctions. Specifically, these conjunctions are used to add further explanation as to the causes of those offences. This phenomenon could 
be interpreted as a concession made by the apologizer to take partial responsibility in the act of apologizing, but the apologizer also wants to give some justification or explanation for the purpose of avoiding full admission of responsibility.

Notably, the ratio of occurrences of conditional apologies to all apologies of sorry-based expressions in written sub-corpus is nearly twice that found in spoken corpora, which could be contributed to the style features of written communication, where people tend to be more tentative and elaborate than in spoken communication in order to be more cautious and polite. This observation could be further investigated in the future to discuss the possible roles that register variations could play in affecting the uses of conditional apologies.

\section{FUNDING}

This paper is supported by the Fundamental Research Funds for the Central Universities (grant no. 15JNYH007) - Constructing a Semantic Knowledge Network of English Words: A Multimodal Perspective.

\section{REFERENCES}

Bisel, R. S., \& Messersmith, A. S. (2012). Organizational and supervisory apology effectiveness: Apology giving in work settings. Business Communication Quarterly, 75(4), 425-448.

Blum-Kulka, S., \& Olshtain, E. (1984). Requests and apologies: A cross-cultural study of speech act realization patterns (CCSARP). Applied Linguistics, 5(3), 196-213.

Brown, P., \& Levinson, S. C. (1987). Politeness: Some universals in language usage (Vol. 4). Cambridge University Press.

Čubajevaitè, L., \& Ruzaitè, J. (2007). Apologies in business communication. Eesti Rakenduslingvistika Ühingu aastaraamat, 3, 67-81.

Davila, J. C. (2004). Forgiveness as a function of offense severity, apology extensiveness, and perceived sincerity: A theoretical model. Unpublished doctoral dissertation. Tulane University, New Orleasn, LA, USA.

Edmondson, W. J. (1981). On saying you're sorry. Conversational routine, 273-288.

Edmondson, W. J., \& House, J. (1981). Let's talk, and talk about it: a pedagogic interactional grammar of English. Urban \& Schwarzenberg.

Eisinger, R. M. (2011). The political non-apology. Society, 48(2), 136-141.

Félix-Brasdefer, J. C. (2010). Intra-lingual pragmatic variation in Mexico City and San Jose, Costa Rica: A focus on regional differences in female requests. Journal of Pragmatics, 42(11), 2992-3011.

Filimonova, V. (2016). Russian and Spanish Apologies: A Contrastive Pragmalinguistic Study. IULC Working Papers, 15(1).
Fraser, B. (1981). On apologizing. Conversational routine, 259-271.

Friedman, H. H. (2006). The power of remorse and apology. Journal of College and Character, 7(1).

Goffman, E. (1955). On face-work: An analysis of ritual elements in social interaction. Psychiatry, 18(3), 213-231.

Goffman, E. (1971). The structure of remedial interchange. Relation in public. New York: Basic Books.

Hoffman, D. A. (2002). The use of apology and employment cases. Employee Rights Quarterly, 2(3), 21-30.

Holmes, J. (1990). Apologies in New Zealand English 1. Language in Society, 19(2), 155-199.

Jebahi, K. (2011). Tunisian university students' choice of apology strategies in a discourse completion task. Journal of Pragmatics, 43(2), 648-662.

Kasper, G. (1988). Variation in interlanguage speech act realization. University of Hawai' $i$ Working Papers in English as a Second Language 7 (2).

Kasper, G. (2000). Data collection in pragmatics research. Culturally speaking: Managing rapport through talk across cultures, 316341.

Kasper, G., \& Blum-Kulka, S. (1993). Interlanguage pragmatics: An introduction. Interlanguage Pragmatics, 3,15 .

Kitao, S. K., \& Kitao, K. (2013). Apologies, apology strategies, and apology forms for non-apologies in a spoken corpus. Journal of Culture and Information Science, $8(2), 1-13$.

Levi, D. L. (1997). The role of apology in mediation. NYUL Rev., 72, 1165.

Meier, A. J. (1992). Brown and Levinson's legacy of politeness. VIenna English Working paperS, 15.

Miller, K. (2014). Conditional and prospective apologies. The Journal of Value Inquiry, 48(3), 403-417.

Norrick, N. R. (1978). Expressive illocutionary acts. Journal of Pragmatics, 2(3), 277-291.

Nureddeen, F. A. (2008). Cross cultural pragmatics: Apology strategies in Sudanese Arabic. Journal of pragmatics, 40(2), 279-306.

Ogiermann, E. (2008). On the culture-specificity of linguistic gender differences: The case of English and Russian apologies1. Intercultural Pragmatics, 5(3), 259-286.

Ogiermann, E. (2009). On Apologising in Positive and Negative Politeness Cultures. Amsterdam \& Philadelphia: John Benjamins.

Olshtain, E. (1989). Apologies across languages. Cross-cultural pragmatics: Requests and apologies, 155173.

Olshtain, E., \& Cohen, A. (1983). Apology: A speech act set. Sociolinguistics and Language Acquisition, 18-35.

Shuman, D. W. (1999). The role of apology in tort law. Judicature, 83, 180.

Trosborg, A. (1995). Interlanguage pragmatics: Requests, complaints, and apologies (Vol. 7). Walter de Gruyter. 


\section{APPENDIX 1}

Collocates of sorry and if followed by but-introduced conjunction in the spoken corpus.

1. I'm sorry if it's one of your bad days, but things will get better.

2. I'm sorry if my behaviour last night caused your wife anxiety, but I have a burning desire to sleep with every woman I meet.

3. Oh sorry if I was being a bit off this morning, but I had about enough.

4. So sorry if I'm harping on and whatever, but it's my job to harp on when the figures are down.

\section{APPENDIX 2}

Collocates of sorry and if followed by but-introduced conjunction in written corpus.

1. Deborah Jeane Palfrey told reporters that she is "genuinely sorry " if people are hurt when identified as clients of her elite escort service - but she has no choice but to call them to prove that her escorts provided only the fantasy of sex.

2. This food is created. I'm as good as anyone. I can eat this as well, and I'm sorry if you feel guilty about me eating it, but this is a meal to be had and I'm going for it.

3. After reviewing Dugan's letter, LaTourette said he was “" sorry if I touched a nerve, but my concern is not for Mr. Dugan's feelings but instead for the thousands of people in Northeast Ohio whose jobs are at risk and the many shareholders of National City Bank
4. I'm sorry if this appears to be looking a gift horse in the mouth but these things do occur.

5. Mr Duncan, in contrast, struck a more measured tone. 'We are sorry if there are many job losses but it is not quite as bad as people feared,' he said.

6. I am sorry if Ken Livingstone has not understood this but I have explained it to him.

7. Sorry if this sounds familiar. However, the message bears repeating, again and again.

8. It's always a takeaway, which costs around GBP 15 for two. Sorry if that doesn't sound very millionaire-ish, but I'm just a normal guy.

9. I am sorry if this whole episode has caused her hurt but to be honest it is not about Penny - it's about business.

10. Naturally, he is sorry if some people were offended, but they should know by now that with Gordon there normally comes some pretty choice language.

11. We are very sorry if this situation happen, but it was only a single incident among plenty of documents we are handling every week.

12. Sorry if that sounded strange but so far my approver was my boss! Thank you for this explanation!

13. I'm sorry if it sounds as though I'm advocating that you blow the whistle on your brother. However, he has had use of the income and should be in a position to pay the tax, whereas your father may not have the money should the taxman chase him, not only for back taxes but also possible penalties for late payment. The pension bombshell should be reviewed. 